This item was submitted to Loughborough's Research Repository by the author.

Items in Figshare are protected by copyright, with all rights reserved, unless otherwise indicated.

\title{
Preservation and stability of cell therapy products: recommendations from an expert workshop
}

\section{PLEASE CITE THE PUBLISHED VERSION}

https://doi.org/10.2217/rme-2017-0073

\section{PUBLISHER}

(c) Future Medicine

\section{VERSION}

AM (Accepted Manuscript)

\section{PUBLISHER STATEMENT}

This work is made available according to the conditions of the Creative Commons Attribution-NonCommercialNoDerivatives 4.0 International (CC BY-NC-ND 4.0) licence. Full details of this licence are available at: https://creativecommons.org/licenses/by-nc-nd/4.0/

\section{LICENCE}

CC BY-NC-ND 4.0

\section{REPOSITORY RECORD}

Stacey, Glyn, Che J. Connon, Karen Coopman, Alan J. Dickson, Barry Fuller, Charles J. Hunt, P. Kemp, et al.. 2017. "Preservation and Stability of Cell Therapy Products: Recommendations from an Expert Workshop". figshare. https://hdl.handle.net/2134/27044. 


\section{Preservation and stability of cell therapy products: recommendations from an expert workshop}

Glyn N Stacey*,1, Che J Connon², Karen Coopman ${ }^{3}$, Alan J Dickson 4 , Barry Fuller ${ }^{5}$, Charles J Hunt ${ }^{1}$, Paul Kemp 6 , Julie Kerby 7 , Jennifer Man'1, Paul Matejtschuk ${ }^{8}$, Harry Moore $^{9}$, John Morris ${ }^{10}$, Richard OC Oreffo ${ }^{11}$, Nigel Slater ${ }^{12}$, Stephen Ward 6 , Claire Wiggins ${ }^{13}$ \& Heiko Zimmermann14,15,16

1UK Stem Cell Bank, Division of Advanced Therapies, NIBSC, South Mimms, Hertfordshire, UK

2Institute of Genetic Medicine, University of Newcastle, Newcastle upon Tyne, UK ${ }^{3}$ Chemical Engineering, Loughborough University, Loughborough, UK 4Manchester Institute of Biotechnology, University of Manchester, Manchester, UK 5 Department of Surgery, University College London, London, UK 6Intercytex Ltd \& HairClone, Manchester, UK 7Cell Therapy Manufacturing Development, Pfizer, Cambridge, UK 8Standardisation Science, National Institute for Biological Standards and Control (NIBSC) a centre of the MHRA, South Mimms, Hertfordshire, UK 9Department of Biomedical Sciences, University of Sheffield, Sheffield, UK 10Asymptote (GE Healthcare), Cambridge, UK ${ }^{11}$ Centre for Human Development, Stem Cells \& Regeneration, University of Southampton, Southampton, UK ${ }^{12}$ The Bioscience Engineering Group, University of Cambridge, Cambridge, UK 13National Health Service - Blood \& Transplant, Watford, UK 14Fraunhofer-Institute for Biomedical Engineering, Sulzbach, Germany 15Department of Molecular \& Cellular Biotechnology/Nanotechnology, Saarland University, Saarbrücken, Germany 16Department of Marine Sciences, Universidad Católica del Norte, Antafogasta/Coquimbo, Chile

*Author for correspondence: glyn.stacey@nibsc.org

Abstract:

If the field of regenerative medicine is to deliver therapies, rapid expansion and delivery over considerable distances to large numbers of patients is needed. This will demand efficient stabilization and shipment of cell products. However, cryopreservation science is poorly understood by life-scientists in general and in recent decades only limited progress has been made in the technology of preservation and storage of cells. Rapid translation of new developments to a broader range of cell types will be vital, as will assuring a deeper knowledge of the fundamental cell biology relating to successful preservation and recovery of cell cultures. This report presents expert consensus on these and other issues which need to be addressed for more efficient delivery of cell therapies. 
Keywords: cell therapy • cold-chain $\bullet$ cryostorage $\bullet$ preservation $\bullet$ regenerative medicine - stability • vitrification

\section{Background}

The ability to reliably preserve cell preparations for therapy and ship them to healthcare centers nationally and internationally presents a key challenge for the delivery of cell therapies. However, the subject of preservation and subsequent shipment, the so-called 'cold-chain,' has received limited support from funding agencies and key scientific and technical challenges remain which present barriers to effective and economic roll-out of new potential cell therapy products. Initiation of an expert Steering Group was led jointly by the Cell and Gene Therapy Catapult and the National Institute for Biological Standards and Control (NIBSC, a center of the Medicines and Healthcare products Regulatory Agency) to develop a strategic framework on key issues in the development of our understanding of the technology for sustaining the stability of cell therapy products for delivery and storage. Representatives of NIBSC and Cell and Gene Therapy Catapult with other experts formed a Steering Group (see Supplementary Appendix 1) to draw together, following a focused workshop, a consensus on key challenges and recommendations to make progress in assuring successful and stable preservation and shipment of cells for therapy. The workshop took place at the NIBSC in May 2015. The remit of the workshop was to garner relevant scientific expertise from industry and academia to address current state of the art, translational gaps in science and technology and areas that require further research. Furthermore, it sought to identify potential ways forward to improve coordination and provision of advice to resolve central issues for companies and healthcare services delivering advanced therapy products. A meeting report from the workshop with recommendations agreed by delegates has since been reviewed by the Steering Group and meeting delegates and is presented here providing an expert consensus for use by research funders, regulatory bodies, healthcare professionals and researchers.

\section{Session 1: Categories of cell systems}

The challenges of preservation are influenced by the nature of individual cells such as their size, membrane permeability, morphology, ultrastructural complexity and composition of subcellular organelles, as well as the cell density and composition of the preservation medium (see reviews in [1-3]). A fundamental underlying factor to cryopreservation in any format is water stress (due to osmotic effects and ice formation), which the group believed to be still poorly understood, and requires further basic research

These defining characteristics are complicated by the presence of multiple cell types or their combination with noncellular components, such as extracellular matrix or artificial scaffolds in certain therapies. While it was clear that a one-size-fits-all approach to preservation of cellular function across such a diverse spectrum of cell therapy products was impracticable, a rationalized approach is needed as the empirically derived processes would not be the same in different systems. While no cell system is completely homogenous, it was concluded that it would be helpful to develop a set of simple cell-based model systems to understand the challenges of preserving key types of cell therapies (see Box 1 
for Recommendation 1). Such cell-based models systems could enable the development of new approaches for preservation and storage at ultra-low or otherwise controlled conditions. It was envisaged that these systems should include a uniform cell suspension type (such as blood-derived T cells), undifferentiated human pluripotent stem cells, cell aggregates (e.g., hepatocytes, neurons) and a combination product such as mixture of fibroblasts and keratinocytes. An overall structure for these model systems should also take into account the processing involved, scale of processing and in particular the time between preparation and delivery to the patient, as illustrated in Figure 1. It will be important to understand the different potential responses of cells in vivo versus in vitro. Furthermore, it would be important in these studies, to minimize the influence of operator variability and the group concluded that automated processing was now sufficiently well developed to provide processing solutions that could eliminate this source of variability.

\section{Session2: Fundamentals of preservation \& recovery}

Successful preservation is dependent on a number of pre-preservation strategies in addition to those already mentioned above. The culture methodology may influence cell morphology and can be adjusted (typically into the logarithmic phase of growth where cells often display a high nuclear/cytoplasmic volume ratio). Cellular permeability may change with temperature which may need to be taken into account for the development of cooling profiles. Water content is clearly a critical issue in cryopreservation of cell preparations but it was recognized that all ultra-low temperature preservation methods ultimately invoked vitrification even if only as a final event during cooling. This has implications for method development and storage conditions [4]. Vitrification by rapid freezing has proven useful in several systems, but suffers from the difficulty in maintaining the integrity of cell-matrix structures, amenability of thawing procedures for routine clinical use [5] and scalability. The group noted that the benefits of vitrification methods had yet to be realized but may be enabled by the development of automated freezing and thawing systems [6-8].

The group considered that one of the major issues, which had held back the development of new and more effective preservation methods, was the com- mon practice in published literature to report measurements of viability immediately post thaw. In the absence of contextualization of the preparation and condition of cells prior to preservation or indeed a suitable timeframe and a short time after recovery (when consequences of the preservation process on viability and cellular function were clearer), this was a confounding issue.

It was recognized that some cellular systems that appear to have similar characteristics may respond very differently to a preservation methods. This observation may be due to differences in their prior expo- sure to environmental conditions, direct or indirect activity of other cells to which they have been exposed and other bioprocessing factors. Approaches to preservation, shipment and recovery would therefore need to take such factors into account and provide coherent records of results (see Box 2 for Recommendation 2). Delivery of cell therapy products to large numbers of patients is unlikely to be achieved using a continuous culture manufacturing process and will require the ability to produce and preserve large batches or necessitate multiple site manufacturing. Closely controlled workflows and culture conditions should increase consistency in the cellular preparations and the ability to recover consistently viable and functional cells. However, it was concluded that the cur- rent reality was that it may be necessary to accept substantial losses of cells and accommodate reason- able recovery 
of adequate cell populations for clinical use. However, as for any preservation process, it would be necessary to demonstrate consistency between the pre- and post-preservation cells to give confidence that potency/efficacy of the cell product for its intended purpose was sustained. The preservation and recovery of cell preparations clearly represents a dynamic process of changing cell condition and snap-shot quality control of cell recovery may be significantly misleading, particularly for cell analysis immediately post thaw. It was, therefore, concluded that at least when developing new or modified preservation methods, recovery of cell preparations needed to be monitored over a period of time post thawing, to create a profile of cell recovery and replication until full functionality was attained.

\section{Session 3: Characterization of cellular preparations}

Traditionally, a pragmatic approach has been adapted to the level of characterization for cell therapy preparations, as to date, most uses of cell therapy have been in urgent treatment of life-threatening conditions such as leukemia. However, given the broad range of applications of cell therapy now under development, the risk/benefit balance may be very different and a greater ability to predict clinical response may be required or mandated by regulators.

The type and level of characterization necessary to demonstrate sustained viability and functionality of the final cell therapy products will depend on the cell type/s involved but should primarily address the demands of their application. The group concluded that in general, for final cell preparations for therapy, it will be important to consider not only markers of features that are expected for therapeutic function, but also markers that are contraindications for clinical use of the cells. The group considered that this area of discussion needed to be explored further through a workshop on cell viability and function (see Box 1 for Recommendation 1).

In the case of pluripotent stem cells the group concluded that current cellular markers may not be sufficient in the absence of functional assays. How- ever, as part of the profile of expression, the cellular markers are important identity markers of the culture type. Nevertheless, functional assays (e.g., teratoma formation in immuno-compromised mice, embryoid body formation in vitro and directed differentiation) are needed to complement currently used markers of self-renewal (e.g., Nanog, Sox2, Oct-4) which are necessary but not sufficient to demonstrate the pluripotent potential of these cells.

Appropriate analytical methods for capturing the properties of cell preparations are often performed at key quality control points in bioprocessing. However, the group identified that these represent snapshots of a dynamic and often evolving cellular system. Mapping this process with in-process testing may well be crucial to successful preservation and recovery of a functional cell therapy product. Examples of clinical and scientific evaluation of primary tissues and cells have been developed in fields such as in vitro fertilisation (IVF) where cells must be used within a few hours.

The group agreed that reference cell preparations may be useful but, in general, for cell therapies where the products are extremely diverse, these may need to be product specific. Nevertheless, the group also concluded that it may be helpful to develop reference materials for the analytical methods used to characterize cell preparations. 
It was recognized that in the development of biotechnology, systems biology studies of the genome and transcriptome had been an important factor in the development of cell culture systems to assess the impact of different culture conditions [9], but relatively few studies had been performed on the impact of preservation [10,11]. The group agreed that further discussion on the application of such deep systems analysis for cell preparations for cell therapy could assist in the assessment of preservation methods. Furthermore, in- depth studies of different combinations of different culture media and matrices using highthroughput approaches are likely to identify improved preservation and stability of models systems as had been developed for gametes [12,13] (see Box 2 for Recommendation 2).

The potentially valuable contribution of low oxygen culture conditions for cells in culture was recognized and recent publications that have demonstrated this for clinically relevant cells - for example in [14-17]. However, specific benefits for preservation and stability of cell preparations had yet to be demonstrated and required further research (see Box 1 for Recommendation 1). In conclusion, future studies of stability for cell therapy systems would need to con- sider culture medium, atmosphere and surface matrix in the context of their impact on cell biology.

The group concluded that experience with a broader range of assays that measured or correlated with cell function, should be developed for the evalu- ation of preservation techniques (see Table 1 \& Box 1 for Recommendation 1) and that studies of model systems (Figure 1) were required.

\section{Session 4: The notion of viability}

It was agreed that there was very little in the literature on thawing of cryopreserved material and there had been modest progress on methodologies for reliable and reproducible thawing. However, the method of thawing can be critical to successful recovery. Various thawing temperatures had been used between 32 and $40^{\circ} \mathrm{C}$ and it was agreed that two key factors in determining the veracity of such data were full and accurate description of the thawing method and records of the actual temperature profile within individual vials. The group noted that there was now equipment available on the market (e.g., ThawSTAR ${ }^{\circledR}$ CFT2 [Medcision, CA, USA] and VIAThaw [Asymptote/GE Healthcare, Cambridge, UK]) which could potentially improve reliability and reproducibility of thawing and recommended that this was an area where rapid improvements could be made (see Box 3 for Recommendation 3) and some progress had already been made in the application of microwave-induced thawing [18].

Understanding of delayed onset cell death in cell preparations post cryopreservation could give valuable information to help improve efficiency and efficacy of cell therapies $[19,20]$. Furthermore, the levels of nonviable cells and cell debris may be important in assessing whether a product is fit for use as these may cause the 
product to cause inflammation or other undesirable responses. Cell death itself is also a complex process that may involve one or multiple different programmed and/or nonprogrammed biochemical processes some of which may be initiated as cell survival processes, such as autophagocytosis. The group agreed that there may be biological consequences of evading cell death, such as genetic change and cell transformation, which could impact on cell function and product safety. Thus, it was clear that viability assessments should go beyond simple enumeration of cell numbers to facilitate a greater understanding of the cell system in question and there was a need for awareness that the same cell preparation can yield different results with different test methods [21-23]. The group concluded that test methods for viability should provide data on both viable and nonviable populations, using a test regime based on a fundamental understanding of the cell preparations in question. In addition, there was a need for more sophisticated approaches to assess cell numbers. The group concluded that a future activity stimulated by the workshop steering group should be to address the needs for evaluation of the quality of in-put or 'feedstock' cells which should incorporate mechanisms of activation of cell death and identification of appropriate surrogate assays of functionality (see Box 4 for Recommendation 4).

While it was broadly recognized that cellular stress is a significant issue to address in successful preservation, this is a complex aspect of cell biology due to the heterogeneity associated with the levels of syn- chronicity, phenotypes of cell populations and the physical heterogeneity of the culture systems. This heterogeneity could include shear force, oxygen, car- bon dioxide etc. Furthermore, it was acknowledged that priming a cell system (e.g., induction of enzymes protective against reactive oxygen species, induction of heat shock protein expression) may influence successful survival after preservation, but relatively little is published in this area and current publications typically deal with preservation of gametes with specialized biological characteristics [24-28] (see Box 2 for Recommendation 2).

\section{Session 5: Formulation of \& delivery of cell therapy products}

In order to facilitate a fundamental re-evaluation of approaches to preservation and stability of cell therapy products it will be important to understand the different formulations in which cells will be delivered to the patient and the cold-chain supply. The transfer of frozen or growth-inhibited cells from central storage to local storage, followed by recovery, formulation and injection to the patient must be considered as a whole process at an early stage in development of the product to generate an effective and efficient delivery chain to enable critical road-blocks to be managed proactively.

\section{Session 6: New technical opportunities \\ Preservation technologies}

Significant effort has been put into freeze-drying cells, however, to date, success has been very limited $[29,30]$. The group concluded that this is clearly an area where further research could have a huge impact in the field of regenerative medicine and beyond. Another important area for development was the identification of new cryoprotective agents. Work was already being carried out with compounds used in nature such as treha- lose, which combined with new cell permeabilization approaches (e.g., bacterial toxins, artificial membrane pores, micelles) [31] could provide new game-changing preservation 
methodologies (see Box 1 for Recommendation 1). Plant and algal cell preservation experience (e.g., Scottish Association for Marine Sciences) and expertise in chemical excipients which modify in vivo structures may also be valuable and are being developed commercially by Croda (East Yorkshire, UK) [32].

Technologies for analysis of cryopreservation systems at ultra-low temperatures, require expertise in physics and materials sciences and include differential scanning calorimetry and neutron scattering and such technologies may have application in the design and evaluation of new methodologies for model systems (Figure 1). The group felt that this and other areas discussed at the workshop would benefit significantly from coordination of existing horizon-scanning activities to spread knowledge of new potential methodologies. Further, this should be linked to a 'test bed' function to provide rapid evaluation and development of generic benefits through qualification of new assays and development of control materials (see Box 4 for Recommendation 4). An example would be high-throughput evaluation of a range of cryoprotectants or protocols (see [13] and below) which could be facilitated by combinatorial experimental tools.

Such tools might include the bead technology developed by Plasticell Ltd (Stevenage, UK) for the study of stem cell differentiation, which apparently can be used with alginate encapsulated cells (personal communication Dr Y Chen, Plasticell Ltd [33]).

\section{Cryoprotectants}

Various cryoprotectant products are on the market but delegates agreed that these were largely based on well-proven methods and reagents. The workshop members felt that there could be real benefits for cell therapies through exploring new approaches and use of novel excipients (e.g., Croda) may also be helpful. Generation of new cryoprotective agents molecules is also an area of active research for some applications [34,35]. Large libraries of such molecules can be synthesized, however, the rate limiting step is testing them with cells under conditions representative of standard cryopreservation.

Delegates concurred that there was a general perception in the field that dimethylsulphoxide (DMSO), the cryoprotectant most commonly used in preservation of cells for clinical use, was undesirable given the broad- ranging and potentially toxic impact on cell biology. It had been proposed that in the long term DMSO should be replaced. The group felt that whilst DMSO could be deleterious under certain circumstances [36], this perception was, to date, causing some companies to consider suboptimal systems for cryoprotection. It was agreed that a published review of the reality of DMSO toxicity would be extremely valuable (see Box 5 for Recommendation 5). This should include the long his- tory of safe use (notably in bone marrow transfusion for more than 40 years), documented adverse events, effectiveness of enhanced removal methods, future need for new alternatives and a way forward to identify and select these. However, the group also agreed on the need to explore alternatives to DMSO through the engagement of chemists, to select and screen appropriate compounds (see Box 1 for Recommendation 1).

Ice-nucleation

The group unanimously agreed that ice nucleation was a critical but largely uncontrollable variable in small sample volumes. This could result in variation in cryopreservation which 
may be observed between individual cryovials filled from the same batch of cell suspension (personal communication, Dr J Morris, Asymptote Ltd./GE Healthcare, Cambridge, UK).

Chemical inducers of nucleation had been developed for addition to preservation medium and some had achieved regulatory acceptance for clinical use. Other technologies included bubbling of nitrogen vapor through the medium which required clinical grade liquid nitrogen. Procedures to assess and control the quality of liquid nitrogen under GMP where some manufacturers consider it a product excipient were required. However, a formal standard for clinical grade liquid nitrogen has yet to be established, although requirements for storage system cryogens are covered in regulatory guidance such as ICH Q8 [37]. Ultra-sonic treatments to induce ice nucleation have also been trialed, but these depend upon inducing cavitation which can cause serious local heating and shock events [38].

\section{Cooling rates}

The use of linear cooling rates is widespread in current technology but it was agreed that few systems achieve truly linear cooling and nonlinear rates or multiramp profiles [39] are known to provide significant improve- ments in cell preservation [40]. Investigation of nonlinear rates could provide some 'quick wins' in the development of new preservation methods. The group proposed that nonlinear cooling rates should be an area for further discussion and coordination. (see Box 4 for Recommendation 4). Furthermore, in order to avoid misinterpretation of cooling rate data, it is important to be sure that the actual cooling rate experienced by the cell preparation is measured during cooling experiments and not just the surrounding environment. New ultrasound-based technologies are currently being used as novel biosensors in cell culture systems (such as those developed by OJ-bio Ltd [41]). These systems could also be considered to monitor cooling rate but may not offer bio-survival data as the technique is dependent on antibody interaction.

\section{Cell \& tissue encapsulation}

Encapsulation has been used in the preservation of a variety of organisms and tissues including bacteria, fungi, plant meristems and disaggregated liver and pancreatic cells [42-45]. The group felt that the potential of this technology, in assisting the stabilization of mammalian cell membranes and avoidance of ice damage, could offer significant advancements in cryopreservation and storage stability. Use of either barium or calcium ion-induced polymerization of alginate was now used widely with mammalian cells which could also be recovered with good viability from alginate capsules following controlled depolymerization. Published examples include fibroblasts [46], disaggregated liver [45], pancreatic islets $[47,48]$ and differentiated pluripotent stem cells [49]. Further- more, novel developments for this approach include syringe preservation.

\section{Session 6: Storage systems}

There was unanimous agreement by delegates that much of the equipment for cooling and storage at ultralow temperatures had not progressed significantly for decades. It was noted that further discussion with manufacturers could yield some progress toward modernization and improvement of their suitability for use with the new generation of cell therapeutics (see Box 4 for Recommendation 4). In contrast, data storage and inventory control were areas where real advances had been made. In particular, it was now possible using radiofrequency identification (RFID) technology (such as being developed by 
CryoGatt Ltd, Hertfordshire, UK [50]) to check inventories of stored material. In addition, the technology had been developed by groups such as IBMT (Fraunhofer Institute, Sulzbach, Germany [51]) which provided an ultra-cold resistant chip within individual cryovials which store the temperature history and detailed cell banking data for each vial. The group concluded that there were now automated access systems (e.g., see [51]) which may provide cost-effective storage and noninvasive temperature monitoring solutions for cell therapies.

\section{Session 7: Thawing methods}

As already detailed, new improved methodologies for thawing are required and new approaches such as ultrasound induced melting and rapid thawing using electromagnetic excitation of nanoparticles may provide suitable solutions for certain applications and are available commercially (e.g., Nano Biosils [52], oi-li- tech nanomaterials [53]). Clearly, the mechanism of heating should be carefully investigated for adverse effects on the cells and compounds to which therapeutic cells are exposed to achieve clinical and regulatory acceptability and approval. However, given that modern vial materials usually restrict heat transfer rates, new methods for rapid and reproducible thawing are urgently needed that provide efficient and rapid thawing to assure adequate cell survival.

\section{Session 8: Storage \& shipment of cells}

Cryoshipments

Shipment of cryopreserved material will continue to add significant cost to the delivery of cell therapies based on current methods. Key issues for shipment of cryopreserved cells which would benefit from new developments include:

- The requirement for stable ultra-low temperatures to be maintained for days or weeks, under, at times, hostile environmental conditions, without interventions such as recharging cryogens by shipping agents.

- Sealing and containment systems that prevent exposure to environmental contamination.

- Robust labeling conventions, standardized product nomenclatures (such as the new WHO INN standard nomenclature for cell therapy products [54]) and labeling materials resistant to ultra-low temperatures and of suitable size to fit on cryovials.

It was noted that there were a number of existing coordinating activities that could provide useful sup- port and in particular the Knowledge Transfer Net- work manufacturing activity on transplantation should be contacted [55] (see Box 4 for Recommendation 4).

Transport of live cultures

The clinical application of cell-based therapeutics has come to the fore, with the number of novel clinical trials demonstrating a dramatic increase in the last decade, accompanied by an emergence of approved cell therapy products to the market. A major bottleneck for cell therapeutics is that the products comprise live cells with short shelf lives. This is a significant challenge for successful completion of quality, safety and efficacy testing, and subsequent distribution from the donor or bank, to sites of processing and back to the clinic. Although cryopreservation is currently to be required for the long-term storage of cells, some cellular systems are not amendable to the application of current methods (discussed above). Thus, the transport of cells in their liquid viable state may be necessary 
or indeed advantageous [56]. In a recent assessment by experts in the field, it was considered critical that improved preservation and transport-enabling technologies be developed in order to eliminate GMP-regulated process steps of preservation removal and cell thawing [57]. This might fit with centralized production facilities for cell therapies, with cryobanking for stock control, followed by thawing and distribution of live cell products.

Hypothermic storage of cells (over a range of $0-34^{\circ} \mathrm{C}$ ), has been recorded to avoid many of the issues associated with cryopreservation. However, delegates still shared concerns over limited time-windows where difficulty in timing the transfer of cells to the clinic due to a restricted, inflexible shelf-life could result in a high level of wastage of materials [58]. Extending the shelf-life of hypothermically stored cellular products, without significant loss of viability and therapeutic potency, could therefore, offer a number of benefits at multiple stages during bioprocessing for both autologous and allogeneic therapies. Extended shelf life would extend the period for completion of quality assurance, sterility testing, characterization and efficacy testing. It would also reduce the risk of wastage due to inadequate continuity between sites of processing and disrupted patient scheduling at the clinic. Additionally, where a course of therapy requires application of repeat tissue samples or cell dosing, multiple products could be stored at the clinic obviating the requirement for multiple shipments.

Current work at the University of Newcastle had developed alginate encapsulation of cells for the hypo- thermic storage of a range of cell types [59]. For some products a combination of cryo-storage and hypothermic storage to obtain the benefits of long-term cryostorage with the ease of handling and reduced ship- ping costs of hypothermic storage of the thawed cells could be advantageous. The group concluded that this approach should be considered as an area with significant potential benefit that would be enhanced by collaboration between academics and manufacturers (see Box 1 for Recommendation 1). Ongoing work at the University of Newcastle was exploring the bio- logical mechanism behind the alginate encapsulation hypothermic storage approach using adipose derived stem cells (stromal fraction) and image analysis at IBMT (see above) has provided useful direct cryomicroscopy evaluation of the cryopreservation process in individual alginate beads.

Live cultures can be shipped with success and the use of so-called 'hibernation media' have been used for many years for therapeutic cells. It was noted that HypoThermasol FRS (BioLife Solutions, WA, USA) with a published composition including DMSO, has been qualified for shipment at $2-8^{\circ} \mathrm{C}$ and is capable of sustaining viability of cell preparations for up to 30days. However, its application in other cells-types had not yet been investigated and the group felt this could be a valuable and straightforward piece of work that could be coordinated between interested researchers and the manufacturer (see Box 3 for Recommendation 3). Shipment at higher temperatures had also been qualified by Organogenesis Inc. [60] who had successfully sustained cell viability following transport at $25^{\circ} \mathrm{C}$ for 5 days and $20^{\circ} \mathrm{C}$ for 15 days. Other approaches to metabolic regulation control may facilitate liquid ambient (around $20^{\circ} \mathrm{C}$ ) temperature which does not appear to necessarily impact on cell viability and function [61-63]. The group felt this deserved further expert discussion to identify the key metabolic changes from $37^{\circ} \mathrm{C}$ down to $20^{\circ} \mathrm{C}$ (see Box 4 for Recommendation 4). The group also agreed that perfluorocarbons for oxygen support [64] and hydrogels also presented potentially valuable reagents to explore 
for cell shipment.

In common with the all-too-many publications of 'successful' cryopreservation methods, publications on hypothermic storage methods (see above) also lacked standardization in terms of validation of success. The value of such publications to industry and healthcare, as well as in taking the science for-ward, was currently limited. The group concluded that this situation could be significantly improved if a set of 'standards' could be agreed that included some quantifiable assessment of functionality relevant to the therapeutic purpose of the product. One such model of potential value has been developed, which establishes a single value combining percentage viable cell release (not simply percentage cell viability) with mitochondrial metabolic activity post-cryopreservation and release [65].

\section{Long-term storage issues}

A range of events were known to cause loss of viability in preserved materials including environmental radiation, poor handling practice (resulting in partial thawing of material), temperature cycling above the glass transition temperature (leading to crystal growth and cell death) and physical shock of vitrified systems causing loss of viability. It is important to understand the factors that determine the critical storage temperature. Studies had shown that human cells can be stored for more than 30 years and that other biological cellular materials for more than 50 years (for a review see [66]). Stability of viability in cryopreserved liquid cell suspensions was known to be very limited at temperatures around $-80^{\circ} \mathrm{C}$ and was totally unsuitable for vitrified material, where the glass transition temperature was much lower, in other words, often below $-150^{\circ} \mathrm{C}$. The manufacturing requirements for storage of cryopreserved materials may vary depending on whether the material is stored short term (e.g., awaiting quality con- trol, shipment) or if the material is in long-term storage such as a manufacturer's master cell bank which may be used over several decades. Approaches, to simulate long- term storage using 'accelerated aging' techniques, have been developed for seeds and protein preparations $[67,68]$ but new approaches may be needed for preserved cells, possibly focusing changes of phase and micro-environment. It was proposed that such approaches should be considered for adaptation for cell therapies. It is clear that long-term storage vessels need to be redesigned to assure low maintenance, well-documented, secure and contamination free systems - this could be the subject of a further workshop sessions with manufacturers, cell biologists, microbiologists, cryobiologists and clinicians (see Box 4 for Recommendation 4).

\section{Conclusion}

It was strongly argued that the broadly held perception that the challenges of cryopreservation were resolved and did not need further development was mistaken and had been a significant reason for the lack of progress in this area. Current press and public interest, in light of recent court rulings on cryonics, only emphasize the need for measured scientific and technological approaches. These along with the application of more relevant characterization of cell biological functions, could lead to significant improvements in yield of viable and functional cells and greater efficiency in cell therapy production chains. It was concluded that these benefits would justify the R\&D investments recommended by the group and furthermore, could reduce the cost of future regenerative medicine products. The recommendations agreed by the workshop delegates are summarized below.

\section{Future perspective}


Once new cell therapies show efficacy there will be an immediate demand for efficient international delivery of cell therapies which will be dependent upon the ability to store and ship cell therapy products stably and reliably. New developments to support this will come from translation of learning from one cell product to another and in considering new solutions to storage and recovery equipment. Investigation and evaluation of new cryoprotectants in different cell systems will also be important in the coming years and research funders should be encouraged to support new coordinated research programs to facilitate early evaluation and translation in industry.

Financial \& competing interests disclosure

The authors have no relevant affiliations or financial involvement with any organization or entity with a financial interest in or financial conflict with the subject matter or materials discussed in the manuscript other than where the company name is given in their affiliation. This includes employment, consultancies, honoraria, stock ownership or options, expert testimony, grants or patents received or pending, or royalties.

No writing assistance was utilized in the production of this manuscript.

\section{Executive summary}

This report summarizes consensus among a specially selected expert group on key issues in assuring stable storage and shipment of cell therapy products.

The discussion covered a broad range of fundamental cell biology and preservation issues which need to be addressed to establish and qualify preservation and storage methods suitable for cell-based medicines.

In particular, the group discussed potential model cellular systems for preservation development and certain neglected but vital aspects of fundamental cell biology and cryopreservation.

They also addressed the need for effective characterization and viability assessment of preserved cells and approaches to formulation of preserved cell-based medicines. Finally, the group also considered new technical opportunities for cryopreservation, storage, shipment and cell thawing.

Workshop recommendations

A number of areas were considered in need of fundamental scientific development and are summarized in Recommendations 1 and 2. Other recommendations addressed potential early benefits that could be obtained from dissemination of current techniques and new instruments (Recommendation 3) and opportunities for advanced understanding of the issues through key coordination activities

(Recommendation 4 and 5).

Conclusion

The group concluded that there were clear and significant benefits to be gained from implementation of these recommendations for effective safe and efficient roll-out of cell therapies.

The issues of cell stability and preservation need to be addressed early in product development and are of particular importance to underpin the current dramatic 
expansion of cell-based medicines such as

immunotherapies including chimeric antibody $\mathrm{T}$ cells. 


\section{References}

1 Pegg D. Principles of cryopreservation. In: Medicines from Animal Cell Culture. Stacey G, Day JM (Eds). John Wiley \& Sons Ltd, NJ, USA, 39-58 (2007).

2 Hunt CJ. Cryopreservation of human stem cells for clinical application: a review. Transfus. Med. Hemother. 38(2),107-123 (2011).

3 Stacey G, Healy H, Mann J, Hunt CJ, Morris J. Fundamental points to consider in the cryopreservation and shipment of cells for human application. Chapter 6. In:

Bioprocessing for Cell-based Therapies. Connon CJ (Ed.). Wiley-Blackwell, NJ, USA, 167-186 (2016).

4 Taylor MJ, Song YC, Brockbank KGM. Vitrification in Tissue Preservation: New Developments. In: Life in the Frozen State. Fuller BJ, Lane N, Benson EE (Eds). CRC Press LLC, FL, USA, 604-641 (2004).

5 Nottola SA, Albani E, Coticchio G et al. Freeze/thaw stress induces organelle remodeling and membrane recycling in cryopreserved human mature oocytes. J. Assist. Reprod. Genet. 33(12), 1559-1570 (2016).

6 Nadarajan J, Pritchard HW. Biophysical characteristics of successful oilseed embryo cryoprotection and cryopreservation using vacuum infiltration vitrification: an innovation in plant cell preservation. PLoS ONE 9(5), e96169 (2014).

7 Shi $\mathrm{M}$, Ling $\mathrm{K}$, Yong $\mathrm{KW}$ et al. High-throughput non- contact vitrification of cell-laden droplets based on cell printing. Sci. Rep. 5, 17928 (2015).

8 Neubauer JC, Beier AF, Stracke F, Zimmermann H. Vitrification in pluripotent stem cell banking: requirements and technical solutions for large-scale biobanks. Chapter 24 In: Vitrification in Assisted Reproduction (Second Edition). Tucker MJ, Liebermann J (Eds.), CRC Press LLC, Boca Raton, FL, USA, 203-224 (2015).

9 Shridhar S, Klanert G, Auer N et al. Transcriptomic changes in $\mathrm{CHO}$ cells after adaptation to resuspension growth in protein-free medium analysed by a species- specific microarray. J. Biotechnol. doi:10.1016/j. jbiotec.2017.03.012 (2017) (Epub ahead of print). Wagh V, Meganathan K, Jagtap S et al. Effects of Cryopreservation on the Transcriptome of Human Embryonic Stem Cells After Thawing and Culturing. Stem Cell Rev. 7(3), 506517 (2011).

Guillaumet-Adkins A, Rodríguez-Esteban G, Mereu E et al. Single-cell transcriptome conservation in cryopreserved cells and tissues. Genome Biol. 18(1), 45 (2017). McGrath J. Predictive models for the development of improved preservation protocols for human oocytes. In: Preservation of Human Oocytes: From Cryobiology Science to Clinic. Borini A, Coticchio G (Eds.), CRC Press, Boca Raton, FL, USA, 62-83 (2009). Pollock K, Budenske JW, McKenna DH, Dosa PI, Hubel A. Algorithm-driven optimization of cryopreservation protocols for transfusion model cell types including Jurkat cells and mesenchymal stem cells. J. Tissue Eng. Regen. Med. doi:10.1002/term.2175 (2016) (Epub ahead of print).

14 Forristal CE, Wright KL, Hanley NA, Oreffo RO, Houghton FD. Hypoxia inducible factors regulate pluripotency and proliferation in human embryonic stem cells cultured at reduced 
oxygen tensions. Reproduction 139(1), 85-97 (2010).

15 Jagannathan L, Cuddapah S, Costa M. Oxidative stress under ambient and physiological oxygen tension in tissue culture. Curr. Pharmacol. Rep. 2(2), 64-72 (2016). Kim DS, Ko YJ, Lee MW et al. Effect of low oxygen tension on the biological characteristics of human bone marrow mesenchymal stem cells. Cell Stress Chaperones. 21(6), 1089-1099 (2016). Tiwari A, Wong CS, Nekkanti LP et al. Impact of oxygen levels on human hematopoietic stem and progenitor cell expansion. Stem Cells Dev. 25(20), 1604-1613 (2016). mesenchymal stromal cells display impaired immunosuppressi
of heat-shock response and impaired interferon- $\square$ licensing Cytotherapy 14(2), 147-152 (2012). Biopreserv. Biobank. 7(1), 3-12 (2009). (2015). (2016). 348-355 (2015).

Mori M, Hayashi T, Isozaki Y, Takenouchi N, Sakatani produced in vitro. J. Reprod. Dev. 61(5), 423-429 (2015). Commun. 479(4), 927-932 (2016). from nature. Integr. Comp. Biol. 45(5), 810-820 (2005).

Manuchehrabadi N, Gao Z, Zhang J et al. Improved tissue cryopreservation using inductive heating of magnetic nanoparticles. Sci. Transl. Med. 9(379), eaah4586 (2017). Baust JM, Vogel MJ, Van Buskirk R, Baust JG. A molecular basis of cryopreservation failure and its modulation to improve cell survival. Cell Transplant. 10(7), 561-571 (2001). Baust JM, Snyder KK, VanBuskirk RG, Baust JG. Changing paradigms in biopreservation.

Altman SA, Randers L, Rao G. Comparison of trypan blue dye exclusion and fluorometric assays for mammalian cell viability determinations. Biotechnol. Prog. 9(6), 671-674 (1993). François M, Copland IB, Yuan S, Romieu-Mourez R, Waller EK, Galipeau J. Cryopreserved mesenchymal stromal cells display impaired immunosuppressive properties as a result Mascotti K, McCullough J, Burger SR. HPC viability measurement: trypan blue versus acridine orange and propidium iodide. Transfusion 40(6), 693-696 (2000).

Puscheck EE, Awonuga AO, Yang Y, Jiang Z, Rappolee DA. Molecular biology of the stress response in the early embryo and its stem cells. Adv. Exp. Med. Biol. 843, 77-128

Aliakbari F, Gilani MA, Amidi F et al. Improving the efficacy of cryopreservation of spermatogonia stem cells by antioxidant supplements. Cell Reprogram. 18(2), 87-95

6 Hofmann N, Sun H, Chatterjee A, Saha D, Glasmacher B. Thermal pretreatment improves viability of cryopreserved human endothelial cells. Biopreserv. Biobank. 13(5), M. Heat shock decreases the embryonic quality of frozen- thawed bovine blastocysts

Setyawan EM, Kim MJ, Oh HJ et al. Spermine reduces reactive oxygen species levels and decreases cryocapacitation in canine sperm cryopreservation. Biochem. Biophys. Res.

Crowe JH, Crowe LM, Wolkers WF et al. Stabilization of dry mammalian cells: lessons

Rao W, Huang $\mathrm{H}$, Wang $\mathrm{H}$ et al. Nanoparticle-mediated intracellular delivery enables cryopreservation of human adipose-derived stem cells using trehalose as the sole 
cryoprotectant. ACS Appl. Mater. Interfaces 7(8), 5017-5028 (2015).

Natan D, Nagler A, Arav A. Freeze-drying of mononuclear cells derived from umbilical cord blood followed by colony formation. PLOS ONE 4(4), e5240 (2009).

Croda. www.croda.com/en-gb

Plasticell.

www.plasticell.co.uk

Briard JG, Poisson JS, Turner TR, Capicciotti CJ, Acker JP, Ben RN. Small molecule ice recrystallization inhibitors mitigate red blood cell lysis during freezing, transient warming and thawing. Sci. Rep. 6, 23619 (2016)

Noha A, Alotaibi S, Slater NKH, Rahmoune H. Salidroside as a novel protective agent to improve red blood cell cryopreservation. PLoS ONE 11(9), e0162748(2016).

Morris TJ, Picken A, Sharp DM, Slater NK, Hewitt CJ, Coopman K. The effect of Me2SO overexposure during cryopreservation on HOS TE85 and hMSC viability, growth and quality. Cryobiology 73, 367-375 (2016).

Pharmaceutical Development: ICH. www.ich.org

Virone C, Kramer HJM, Van Rosmalen GM, Stoop AH, Bakker TW. Primary nucleation induced by ultrasonic cavitation. J. Cryst. Growth. 294(1), 9-15 (2016).

Skorobogatova N, Novikov AN, Fuller BJ, Petrenko AY. Importance of a three-stage cooling regime and induced ice nucleation during cryopreservation on colony-forming potential and differentiation in mesenchymal stem progenitor cells from human fetal liver. Cryo Lett. 31(5), 371-379 (2010).

Massie I, Selden C, Hodgson H, Fuller B, Gibbons S, Morris GJ. GMP cryopreservation of large volumes of cells for regenerative medicine: active control of the freezing process. Tissue Eng. Part C Methods 20(9), 693-702 (2014).

OJ-Bio. www.oj-bio.com/

Benelli C, De Carlo A, Engelmann F. Recent advances in the cryopreservation of shootderived germplasm of economically important fruit trees of Actinidia, Diospyros, Malus, Olea, Prunus, Pyrus and Vitis. Biotechnol. Adv. 31(2), 175-185 (2013).

Hong SR, Yin MH. High-efficiency encapsulation- vitrification protocols for cryopreservation of embryogenic calli of the oriental medicinal plant Anemarrhena asphodeloides Bunge. Cryo Lett. 33(3), 191-201 (2012).

4 Juárez Tomás MS, De Gregorio PR, Leccese Terraf MC, Nader-Macías ME. Encapsulation and subsequent freeze- drying of Lactobacillus reuteri CRL 1324 for its potential inclusion in vaginal probiotic formulations. Eur. J. Pharm. Sci. 79, 87-95 (2015).

Kilbride P, Gonzalez-Molina J, Maurmann N et al. Impact of storage at $-80^{\circ} \mathrm{C}$ on encapsulated liver spheroids after liquid nitrogen storage. Biores. Open Access 5(1), 146154 (2016).

Mohanty S, Wu Y, Chakraborty N, Mohanty P, Ghosh G. Impact of alginate concentration 
on the viability, cryostorage, and angiogenic activity of encapsulated fibroblasts. Mater.

Sci. Eng. C Mater. Biol. Appl. 65, 269-277 (2016). Open Access 2(1), 1-11 (2013).

Agudelo CA, Teramura Y, Iwata $\mathrm{H}$. Cryopreserved agarose-encapsulated islets as bioartificial pancreas: a feasibility study. Transplantation. 87(1), 29-34 (2009).

Schneider S, Klein HH. Long-term graft function of cryostored alginate encapsulated rat islets. Eur. J. Med. Res. 16(9), 396-400 (2011).

Konagaya S, Iwata $\mathrm{H}$. Microencapsulation of dopamine neurons derived from human induced pluripotent stem cells. Biochim. Biophys. Acta 1850(1), 22-32 (2015).

Cryogatt Systems Ltd. www.cryogatt.com/

Fraunhofer IBMT. www.ibmt.fraunhofer.de/

Nano Biosols.

www.nanobiosols.com/gold-nanoparticles-2-c.asp

IoLiTec Nanomaterials. www.nanomaterials.iolitec.de/en/

WHO. INN Nomenclature Scheme For Cell Therapy Products (CTP).

www.who.int/medicines/services/inn/INN_CTS_2015

Innovateuk. HealthTech and Medicines.

https://connect.innovateuk.org/web/healthktn/overview

Pamphilon DH, Selogie E, Szczepiorkowski ZM. BEST collaborative cellular therapies team. Vox Sang. 99(2), 168-173 (2010).

Hourd P, Ginty P, Chandra A, Williams DJ. Manufacturing models permitting roll out/scale out of clinically led autologous cell therapies: regulatory and scientific challenges for comparability. Cytotherapy 16(8), 1033-1047 (2014).

Hernon CA, Dawson RA, Freedlander E et al. Clinical experience using cultured epithelial autografts leads to an alternative methodology for transferring skin cells from the laboratory to the patient. Regen. Med. 1(6), 809-821 (2006).

Chen B, Wright B, Sahoo R, Connon CJ. A novel alternative to cryopreservation for the short-term storage of stem cells for use in cell therapy using alginate encapsulation. Tissue Eng. Part C Methods 19 (7), 568-576 (2013).

Organogenesis Inc. www.organogenesis.com/

Wang J, Wei Y, Zhao S et al. The analysis of viability for mammalian cells treated at different temperatures and its application in cell shipment. PLOS ONE 12(4), e0176120 (2017).

Wang J, Chen P, Xu J, Zou JX, Haibin Wang H, Chen HW. Transporting cells in semisolid gel condition and at ambient temperature. PLOS ONE 10(6), e0128229(2015).

Jiang B, Yan L, Miao Z, Li E, Wong KH, Xu RH. Spheroidal formation preserves human stem cells for prolonged time under ambient conditions for facile storage and transportation. Biomaterials 133, 275-286 (2017).

Erro E, Bundy J, Massie I et al. Bioengineering the liver: scale-up and cool chain delivery of the liver cell biomass for clinical targeting in a bioartificial liver support system. Biores. 
Swioklo S, Constantinescu A, Connon CJ. Alginate- encapsulation for the improved hypothermic preservation of human adipose-derived stem cells. Stem Cells Transl. Med. 5, 339-349 (2016). Stacey GN, Day JG. Long-term ex situ conservation of biological resources and the role of biological resource centres. Methods Mol. Biol. 368, 1-14 (2007). Matejtschuk P, Phillips P. Product stability and accelerated degradation studies. In: Medicines from Animal Cell Culture. Stacey G, Day JM (Eds). John Wiley \& Sons Ltd, NJ, USA, 503-522 (2007). degradation of therapeutic proteins. J. Pharm. Sci. 101(3), 895-913 (2012).

\section{Figures and Tables:}

\section{Box 1. Recommendation 1.}

A coordinated program of research into cryopreservation methods using relevant exemplars from cell therapy. This would include:

Development of a set of simple model systems that could be used to understand the challenges of preserving key types of cell therapies

A large study investigating different media and matrices for preservation of model systems engaging expertise in - omics analysis

Further R\&D funding for investigation of cell freeze-drying and cell permeabilization methods that could provide game-changing discoveries Investigation of alternative cryoprotectants to dimethylsulphoxide which engages chemistry expertise to select and screen appropriate compounds Investigation of a combinatorial approach combining cryopreservation with hypothermic storage 

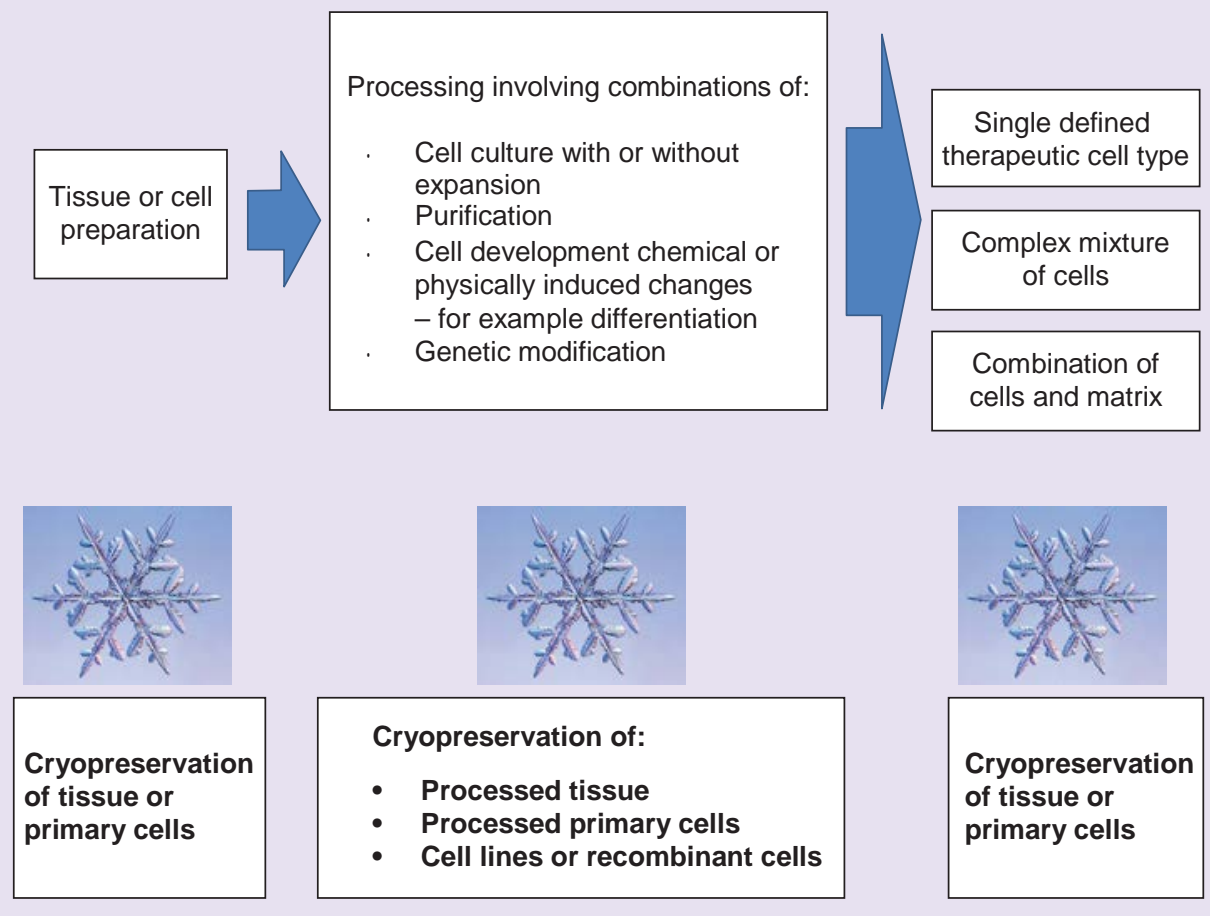

Figure 1. Potential models systems to assess new preservation strategies.

Donor cell harvest to recipient time:

b) Hours: risk assessment similar to transplantation and bioprocessing should assure little or no change in the cell preparation.

c) Days: key additional hazard is expansion of microbial, contamination requiring new rapid methods and loss of viability and efficacy requiring careful characterization.

d) Preservation steps for seed stock enable long-term storage of seed stocks, intermediate cell preparations and final product thus permitting careful characterization and safety testing to provide greater confidence in efficacy and safety.

\section{Box 2. Recommendation 2.}

A coordinated research program into the fundamental elements of cell biology associated with stability and successful preservation. This should include:

The development and application of more appropriate and quantified measurement of viability and survival specified for particular applications, including epigenetic, metabolomics and transcriptomic profiling Careful comparative studies to elucidate the benefits of well controlled hypoxic culture conditions for

therapies

Table 1. Levels of analysis for evaluation of viability and function for cell therapies. Feature of cell biology Methods and exemplar studies 


\begin{tabular}{|c|c|}
\hline $\begin{array}{l}\text { Membrane integrity/function (and } \\
\text { lipidomics) }\end{array}$ & $\begin{array}{l}\text { Membrane associated enzymes } \\
\text { (fluorescein diacetate test for membrane } \\
\text { esterases), membrane degradation test } \\
\text { such as malondialdehyde assay, } \\
\text { lipidomics }\end{array}$ \\
\hline $\begin{array}{l}\text { Structure and function of subcellular } \\
\text { organelles }\end{array}$ & $\begin{array}{l}\text { Mitochondria, nucleus, endoplasmic } \\
\text { reticulum, protein folding }\end{array}$ \\
\hline $\begin{array}{l}\text { Biochemical pathways and key molecular } \\
\text { complexes }\end{array}$ & $\begin{array}{l}\text { Proteasome, epigenome, transcriptome } \\
\text { and metabolome }\end{array}$ \\
\hline Metabolic flux & Mitochondrial functions \\
\hline Adherence mechanisms & Integrin expression \\
\hline Single cell analysis & $\begin{array}{l}\text { Studies of subpopulation analysis using live } \\
\text { cell imaging, Matrix-assisted laser } \\
\text { desorption/ } \\
\text { ionization (MALDI), Raman spectroscopy, } \\
\text { single cell analysis (e.g., sequencing, } \\
\text { expression profiling) } \\
\text { electrophysiology, cryomicroscopy among } \\
\text { others. }\end{array}$ \\
\hline Image analysis and morpholomics & $\begin{array}{l}\text { New approaches to applying metrics to } \\
\text { cell morphology such as neurite } \\
\text { outgrowth }\end{array}$ \\
\hline Cell functionality and response & $\begin{array}{l}\text { Real-time measurement of calcium } \\
\text { imaging Response to reference } \\
\text { compounds including TNF- } \square \text { and toxicants }\end{array}$ \\
\hline Rate of cell death & $\begin{array}{l}\text { Assessment of rates of replication and } \\
\text { death }\end{array}$ \\
\hline \multicolumn{2}{|c|}{$\begin{array}{l}\text { Box 3. Recommendation } 3 . \\
\text { The group identified areas where translation of current knowledge and expertise } \\
\text { could lead to early improvements in current preservation and shipment technology } \\
\text { and these included: } \\
\text { Investigation of 'hibernation media' which had proved successful with some cell } \\
\text { types and their assessment for broader application with cell therapy preparations } \\
\text { Use of newly available thawing equipment to improve reliability of thawing and viable } \\
\text { cell yield }\end{array}$} \\
\hline
\end{tabular}

Box 4. Recommendation 4. 
The group proposed that further interaction between academic, commercial and regulatory stakeholders should be promoted in meetings and workshops specifically in the following areas:

Coordination of current horizon-scanning activities to spread knowledge of new potential methodologies. This should be linked to a 'test bed' function to provide rapid evaluation and development of generic benefits through qualification of new assays and control materials

Assessment of the requirements for long-term storage systems to assure lowmaintenance, well-documented, secure and contamination-free systems and the development of accelerated ageing studies which could be useful for cell therapies Workshop activity should include manufacturers, cell biologists, microbiologists, cryobiologists and clinicians

Address the needs for evaluation of the quality of 'feedstock' cells or starting cultures, incorporating consideration of mechanisms of activation of cell death and identification of appropriate assays of viability and function

Evaluation of the value that nonlinear cooling rates might hold for improvement in preservation technology

The impact of ambient temperature storage on cell biology

Cross agency coordination should be promoted including the Knowledge Transfer Network (KTN) manufacturing activity on transplants

Box 5. Recommendation 5.

The group identified that a published review addressing the reality of dimethylsulphoxide toxicity would be extremely valuable. This should include history of use, documented adverse events, effectiveness of enhanced removal methods, future need for new alternatives and a way forward to identify and select these 